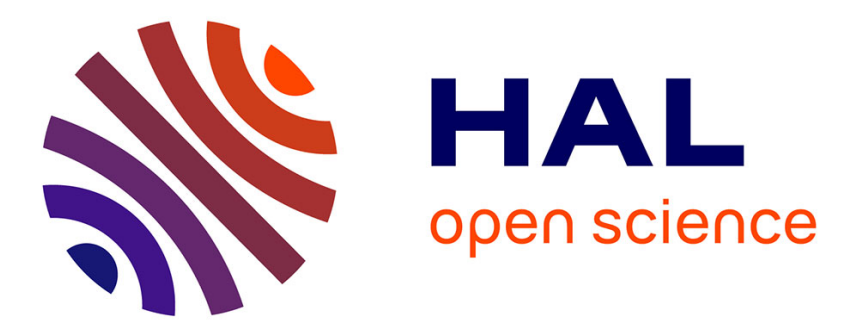

\title{
Colorectal endometriosis and fertility
}

Emile Daraï, Jonathan Cohen, Marcos Ballester

\section{To cite this version:}

Emile Daraï, Jonathan Cohen, Marcos Ballester. Colorectal endometriosis and fertility. European Journal of Obstetrics \& Gynecology and Reproductive Biology, 2016, 10.1016/j.ejogrb.2016.05.024 . hal-01331048

\section{HAL Id: hal-01331048 https://hal.sorbonne-universite.fr/hal-01331048}

Submitted on 13 Jun 2016

HAL is a multi-disciplinary open access archive for the deposit and dissemination of scientific research documents, whether they are published or not. The documents may come from teaching and research institutions in France or abroad, or from public or private research centers.
L'archive ouverte pluridisciplinaire HAL, est destinée au dépôt et à la diffusion de documents scientifiques de niveau recherche, publiés ou non, émanant des établissements d'enseignement et de recherche français ou étrangers, des laboratoires publics ou privés. 


\section{Colorectal endometriosis and fertility}

Emile Daraï, Jonathan Cohen, Marcos Ballester

Department of Gynecology and Obstetrics, Hôpital Tenon, Assistance Publique des Hôpitaux de Paris, UMRS-938, Université Pierre et Marie Curie Paris 6, Groupe de Recherche Clinique (GRC 6-UPMC), Centre Expert en Endométriose (C3E), France.

\section{Corresponding author}

Professor Emile Daraï, MD, PhD

E-mail: emile.darai@aphp.fr

Department of Gynaecology and Obstetrics

Hôpital Tenon, AP-HP

4 rue de la Chine, 75020, Paris, France

Tel.: +331560173 18; Fax: +33156017317

No funding or research contract or conflict of interest. 


\section{Abstract}

Objective: The goal of this review was to assess the impact of colorectal endometriosis on spontaneous fertility and the potential benefit of Medically Assisted Reproduction (MAR) (in vitro fertilization and intrauterine insemination) and surgery on fertility outcomes.

Study design: MEDLINE search for articles on fertility in women with DIE published between 1990 and December 2015 using the following terms: "deep endometriosis", "deep infiltrating endometriosis", "bowel endometriosis", "colorectal endometriosis", "fertility", “infertility”, "IVF-ICSI”, “Assisted Reproductive Techniques (ART)”, and "MAR”.

Results: Spontaneous pregnancy rate (PR) in patients undergoing resection of DIE but leaving in situ colorectal endometriosis was 26.5\% (95\% CI = 14-39). PR after MAR was $27.4 \%(95 \% \mathrm{CI}=19-35)$ and the overall $\mathrm{PR}$ was $37.9 \%(95 \% \mathrm{CI}=29-37)$. After colorectal surgery, among the 855 patients with and without proved infertility, the spontaneous PR was $31.4 \%(95 \% \mathrm{CI}=28-34)$ without difference between the groups. PR after MAR was $19.8 \%$ $(95 \% \mathrm{CI}=17-22) . \mathrm{PR}$ after MAR in patients with and without proved infertility was $21.4 \%$ $(95 \% \mathrm{CI}=18-25)$ and $15.5 \%(95 \% \mathrm{CI}=11-20)$, respectively. The overall PR after colorectal surgery was $51.1 \%(95 \% \mathrm{CI}=48-54)$.

Conclusion: Our review supports a potential benefit of surgery on fertility outcomes for women with colorectal endometriosis. Further studies are required to determine whether surgical management should be first-intention or restricted to failure of MAR.

Key words: endometriosis, deep infiltrating endometriosis, colorectal endometriosis, surgery, fertility, Medically Assisted Reproduction, Assisted Reproductive Therapy 


\section{Condensation:}

Colorectal resection is associated with an increased in pregnancy rate in patients with prior infertility associated with endometriosis or wishing to conceive without true infertility. 


\section{Introduction}

Endometriosis, a well-known cause of pain and infertility affecting 10 to $15 \%$ of women of childbearing age, is defined histologically by the presence of endometrial glands and stroma outside the uterus [1]. Deep infiltrating endometriosis (DIE), defined by the European Society of Human Reproduction and Embryology (ESHRE) as the infiltration of endometriotic tissue by more than $5 \mathrm{~mm}$ beneath the peritoneum, is estimated to affect more than $20 \%$ of women with endometriosis and as many as $55 \%$ of patients referred to specialized centers [2-5].

Among the various locations of DIE lesions, colorectal endometriosis, involving the rectosigmoid junction and rectum, represents the most severe form affecting 5.3 to $12 \%$ of women with endometriosis [6,7] and accounting for more than $90 \%$ of all bowel endometriosis [8-14]. As colorectal endometriosis is often associated with other lesions involving the uterosacral ligaments, torus uterinum, parametrium, vagina, as well as the ovaries, the impact of colorectal endometriosis alone on fertility is unclear $[8,10,12,13]$. In addition, these endometriotic lesions are often associated with external or internal adenomyosis that can also alter fertility outcomes [15]. Despite numerous published reports, there is a lack of data on spontaneous pregnancy in patients with colorectal endometriosis and risk factors of infertility thereby remain poorly identified. The meta-analysis of Adamson et al., demonstrated that surgical removal of lesions in women with ASRM stage III-IV (American Society of Reproductive Medicine classification) was associated with an increased spontaneous pregnancy rate (PR) with a differential gain in pregnancy of $39 \%$ [16]. Along with the ASRM classification which is widely used to stage DIE, the ENZIAN-score was developed more recently. Both classifications have their strong and weak points: on one hand the ASRM classification evaluates intraperitoneal abnormalities associated with 
endometriosis but does not take into account the presence of DIE lesions, and on the other, the ENZIAN-score evaluates DIE lesions but does not consider intraperitoneal endometriotic locations. For these reasons, a new classification is justified taking into account both intraand subperitoneal endometriotic lesions [17].

Another concern is the absence of consensus about indications for colorectal surgery for infertility as well as the type of surgery (rectal shaving, discoid excision or segmental resection) [18]. Moreover, interpretation of fertility results after colorectal surgery is difficult, as most authors fail to distinguish patients with true infertility from those wishing to conceive without proved infertility (no attempt to being pregnant longer than one year preoperatively) and for whom a first line MAR is rapidly proposed).

Therefore, the aims of the present review were to evaluate the impact of colorectal endometriosis on fertility and the contribution of medically assisted reproduction (MAR) and of colorectal surgery on fertility outcomes in women with and without preexisting proved infertility.

\section{Methods}

We used the methodology recommended by the Prisma statement for reviews and meta-analyses. The literature research was conducted in Medline, Embase and the Cochrane Library and was limited to studies published in English and French between January 1990 and November 2015. The Mesh Database of Pubmed helped steer the search by combining the following Mesh keywords: “deep endometriosis”, “deep infiltrating endometriosis”, "bowel endometriosis" and "colorectal endometriosis" associated with the terms "fertility", “infertility", "IVF-ICSI”, “Assisted Reproductive Techniques (ART)" and "MAR”. To ensure the relevance of the publications we also only included articles that: distinguished between women wishing to conceive and infertile women defined by the absence of conception after one year of attempt; described fertility outcomes before and after surgery; and reported the 
type of surgery. We removed all redundant articles from the initial screening as well as those where the title, abstract or material and methods did not fit the aims of our work (Figure 1).

In this review, we use the World Health Organization International Committee Monitoring Assisted Reproductive Technologies (WHO ICMART) definitions: ART (including in vitro fertilization (IVF), embryo or gamete intrafallopian transfer, zygote intrafallopian transfer, tubal embryo transfer, gamete and embryo cryopreservation, oocyte and embryo donation, and gestational surrogacy); and MAR (including ovulation induction, controlled ovarian stimulation, ovulation triggering and intrauterine insemination (IUI) using sperm from either a partner or sperm donor) $[19,20]$.

\section{Issues on fertility and colorectal endometriosis.}

The main issue with colorectal endometriosis is to prove the relation between the presence of bowel endometriosis and infertility. In addition to a previous meta-analysis demonstrating the low spontaneous PR especially in women with advanced stages of the disease [21], Eijkemans et al. evaluated the chance of pregnancy on an IVF-ICSI waiting-list of couples with various causes of infertility [22]. They found that the cumulative probability of treatment-free ongoing pregnancy was $9 \%$ at 12 months. Diagnostic categories showed that the lowest hazard ratio was noted for women with endometriosis $(0.7$ compared with those with tubal infertility) demonstrating the negative impact of endometriosis on spontaneous pregnancy. However, this study did not distinguish between women with endometriosis those with colorectal lesions.

Another issue is the use of a consensual anatomical and surgical terminology when comparing series. Some authors define rectovaginal septum (RVS) endometriosis as endometriosis involving visceral fascia located between the vagina and rectum with or without extension to the uterosacral ligaments or to the vagina but without bowel 
endometriosis [18], while others include obliteration of the pouch of Douglas with or without colorectal infiltration under the term RVS [23].

From a surgical point of view, there is also some ambiguity concerning surgical procedures. For example, Donnez et al. [24] defined shaving as a separation of the anterior from the posterior vagina, an excision or ablation of DIE after complete dissection of the nodule from the posterior part of the cervix, systematically removing the posterior vaginal fornix while Meuleman et al. [18] defined rectal shaving as superficial peeling of bowel serosal and subserosal endometriosis. Six studies assessed the impact of surgery on fertility outcomes in women with RVS endometriosis [24-29] but none of them distinguished between women with and without colorectal endometriosis. These six studies were thus excluded from the present review.

Finally, in accordance with previous studies [18], we suggest the following definitions: rectal shaving as the superficial serosal and subserosal excision of endometriosis not requiring suturing or closuring; rectal partial thickness excision (also called deep rectal shaving) as excision of the rectal muscularis excision without opening the rectal mucosa but requiring suturing or closuring; rectal full thickness excision as the entire resection of the rectal wall including the mucosa whatever the technique used and including open full thickness discoid excision followed by suture or closure and closed full thickness discoid excision using stapler; and colorectal resection as segmental resection. The novel laparoscopic and transanal resection of lower- and mid-rectal endometriosis, also called the Rouen technique, is considered a rectal full thickness resection [30]. To analyze fertility outcomes, we also distinguished series with in situ colorectal endometriosis composed of women undergoing no colorectal surgery neither rectal shaving. Conversely, the colorectal surgery group was composed of women who had had colorectal surgery whatever the technique and including superficial rectal shaving. 


\section{Spontaneous fertility in women with in situ colorectal endometriosis}

To our knowledge, only one study to date has assessed fertility outcomes without surgery in a population of women with RVS endometriosis but without clearly identifying those with bowel involvement [25]. In this series, two groups of patients were distinguished; the expectant management group composed of 61 patients and the surgery group composed of 41 patients. Twenty-two of the 61 women $(36 \%)$ included in the expectant management group conceived: three spontaneous pregnancies $(13 \%)$, four after ovarian stimulation and 15 after IUI. During a mean follow-up period of 24 months, the cumulative PR was $46.8 \%$ [25]. Recently, Roman et al. [30] provided supplementary data on spontaneous PR from Bianchi et al. study. Ten of 115 women opting for first IVF treatment conceived spontaneously $(\mathrm{PR}=8.7$ $\%)$. However, the proportion of women with colorectal involvement in this study was not clearly identified in the initial report. This spontaneous PR is in agreement with those of previous studies, not focusing on a population with colorectal endometriosis, reporting a spontaneous PR of about $10 \%[22,31]$.

Two studies have evaluated the spontaneous PR in women undergoing resection of DIE but leaving in situ colorectal endometriosis [32,33] (Table 1). The spontaneous PR was $26.5 \%$ $(95 \% \mathrm{CI}=14-39)$ (Figure 2). However, the results of these studies are too different to be able to draw a definite conclusion about this option. 


\section{Fertility after MAR in women with in situ colorectal endometriosis}

Despite encouraging data on fertility after discoid resection of colorectal endometriosis [34], due to the relatively high rate of complications - including neurogenic bladder, rectovaginal fistulae and anastomotic dehiscence - subsequent to colorectal surgery mainly involving segmental resection [18], physicians often opt for MAR in the context of infertility rather than select patients who may benefit from prior surgery with potential spontaneous pregnancy. This first-intention MAR option would appear to be suitable as a previous study [35] demonstrated that, with the exception of women with endometrioma, infertile women with various stages of endometriosis have the same PR rates in IVF-ICSI than those with tubal factor. In a preliminary study [36] Mathieu d'Argent et al., found a PR after one IVFICSI cycle of $41 \%$. Moreover, in accordance with a previous study [35], no difference in PR was noted between women with colorectal endometriosis and those with tubal or male infertility. Subsequently, in a multicenter study including the women from Mathieu d'Argent et al.'s series, Ballester et al. [37] showed that the cumulative PRs after one and two IVF-ICSI cycles were 29.3 and $52.9 \%$, respectively. In this specific setting, we are currently waiting for the results of an ongoing trial comparing first-intention MAR and colorectal surgery in women with patent fallopian tubes and without associated male infertility to build a therapeutic strategy.

Three studies reported the PR after MAR including the two previously mentioned series with resection of DIE and leaving in situ colorectal endometriosis [32,33] and one including patients with no surgery [37] $(\mathrm{PR}=27.4 \%(95 \% \mathrm{CI}=19-35))($ Figure 3$)$. The overall $\mathrm{PR}$ was $37.9 \%(95 \% \mathrm{CI}=29-47)$. 


\section{Spontaneous fertility after surgery for colorectal endometriosis}

The main issue is when to opt for surgery in the context of infertility associated with colorectal endometriosis. In our institution, except for women with tubal pathology or associated male infertility requiring systematic IVF-ICSI management, if pregnancy is the priority for the woman we opt for first-intention IVF-ICSI treatment due to the lack of data proving the superiority of surgery over MAR. This option offers a high cumulative PR till two cycles. After failure of two IVF-ICSI cycles, we recommend a colorectal surgery as there is little benefit on the cumulative PR of adding further cycles. Moreover, this strategy is supported by the possibility of spontaneous pregnancy after surgery even in patients experiencing failure of IVF-ICSI and that only four IVF-ICSI cycles are reimbursed by the French health system.

Other authors recommend first-intention surgery in the context of infertility associated with colorectal endometriosis due to the resulting high spontaneous PR. The influence of bowel endometriosis on spontaneous fertility and the impact of surgery was evaluated in a controlled non-randomized study [32]. Among the 155 women who had been infertile for over two years, three groups were defined: group A consisted of 60 women undergoing both DIE and colorectal resection; group B of 40 women undergoing DIE removal leaving in situ colorectal endometriosis; and group $\mathrm{C}$ of 55 women without bowel endometriosis undergoing DIE removal. With a mean follow-up of 27 months, spontaneous PR in groups A and B were $40 \%$ and $30 \%$, respectively [32]. Overall, the PR was higher in group C (i.e., women without bowel endometriosis) but no difference in spontaneous PR was observed between groups A and B. Two interpretations of the results are possible. First, removal of all endometriotic lesions including resection of colorectal endometriosis results in a higher PR. Second, the absence of difference in PR between groups A and B groups suggests a low impact of colorectal endometriosis while removal of other DIE lesions plays a crucial role on fertility. 
Recently, Meuleman et al. reported the impact of colorectal surgery on fertility [38]. Among 48 women undergoing a colorectal surgery with at least one patent fallopian tube, $38 \%$ became pregnant spontaneously. However, it was impossible to distinguish between women with proved infertility from those wishing to conceive without proved infertility. These results are in agreement with those of a randomized trial comparing open to laparoscopically assisted colorectal resection for endometriosis showing that $40 \%$ of the women became spontaneously pregnant after surgery [39]. Moreover, all spontaneous pregnancies occurred after laparoscopic surgery while no spontaneous pregnancies were observed either in the open surgical group or after laparoconversion.

In the present review, data on spontaneous fertility after surgical treatment of endometriosis with colorectal endometriosis were available in 26 series from 1990 to 2015 including 1968 patients (Table 2) $[9,13,32,38-57,34]$. The design and the populations of the series differed significantly and there were no randomized studies focusing on fertility. Among the 855 women with proved infertility or wishing to conceive without proved infertility, 31.4\% (95\% CI = 28-34) became pregnant spontaneously (Figure 4). Spontaneous PR in women with and without proved infertility was $31.4 \%(95 \% \mathrm{CI}=28-35)($ Figure 5) and $31.1 \%(95 \% \mathrm{CI}=25-37)$ (Figure 6), respectively. These results support the potential benefit

of colorectal surgery on spontaneous PR when compared to PR in women treated by expectant management.

\section{Results of MAR on fertility after colorectal resection for endometriosis}

The ESHRE guidelines state that the effectiveness of surgical excision of deep nodular lesions before MAR treatment in women with endometriosis-associated infertility is not well established in terms of reproductive outcome [5]. 
A recent French retrospective study [58] reported no difference in PR and birth rate after IVF-ICSI between women with no surgery, incomplete and complete removal of endometriotic lesions. In this study, 177 women with DIE were included, 65 in the IVF without surgery group, 49 in the complete surgery group and 63 in the incomplete surgery group (adhesiolysis, cystectomy, ovariectomy, salpingectomy, tubal surgery or partial DIE removal). Pregnancy rates and live birth rates per women were similar in the 3 groups: $46.2 \%$ and $33.9 \%$ in the IVF without surgery group, $51 \%$ and $30.5 \%$ in the complete surgery group and $41.3 \%$ and $35.6 \%$ in the incomplete surgery group. However, this study did not specifically assess the outcomes in women with colorectal involvement. Moreover, the rate of miscarriage after complete removal was twice as high in the group of complete surgery compared to the two others. These results are in contrast with those of Stepniewska et al. [32] who report a higher overall PR (both spontaneous and after MAR) in women undergoing colorectal resection but no difference in the spontaneous PR between women undergoing DIE surgery with colorectal resection or leaving in situ colorectal endometriosis. Indeed, the pregnancy rate was lower when bowel endometriosis was not remove (group A and B compared with group $\mathrm{C}$ ). The monthly fecundity rate in groups $\mathrm{A}, \mathrm{B}$ and $\mathrm{C}$ were $2.3 \%, 0.84 \%$ and $3.95 \%$, respectively $(\mathrm{P}<0.05)$. These data support the idea that the presence of bowel infiltration by endometriosis negatively influences the reproductive outcome and that complete removal of endometriosis with colorectal resection enhances fertility.

In the present review (Table 2), the overall PR after colorectal resection was $51.1 \%$ $(95 \% \mathrm{CI}=48-54)$ underlining the relatively limited contribution of MAR in this specific population (Figure 7). Indeed, the differential benefit of MAR on overall PR was $19.8 \%(95 \%$ $\mathrm{CI}=17-22)($ Figure 8$)$. When considering PR after MAR in women with and without proved infertility, the values were $21.4 \%(95 \% \mathrm{CI}=18-25)($ Figure 9$)$ and $15.5 \%(95 \% \mathrm{CI}=11-20)$ (Figure 10) suggesting a greater benefit for patients with proved infertility. When comparing 
IUI and IVF-ICSI, the contribution of IUI appears minimal which supports systematic firstintention management by IVF-ICSI.

\section{Limiting factors when evaluating fertility in women with colorectal endometriosis.}

Fertility in women with colorectal endometriosis requires careful analysis, especially after surgery. As previously mentioned, the term surgery for colorectal endometriosis comprises various types such as segmental resection, rectal shaving or discoid resection. Due to the difficulties of clearly identifying fertility outcomes after discoid resection or rectal shaving, it is difficult to analyze the specific contribution of these surgical approaches on fertility. Moreover, the majority of studies on colorectal surgery for endometriosis gave the median age of the whole population but median age in the subgroup of patients wishing to conceive or with infertility is often missing. However, encouraging data exist relating the postoperative fertility in women managed with disc excision [59].

Previous studies $[37,44]$ have reported a lower PR in women with endometriosis associated with adenomyosis. However, these authors did not distinguish between external and internal adenomyosis or between diffuse and focal adenomyosis. Ballester et al. [37] demonstrated the negative impact of adenomyosis on PR with no additional pregnancy being obtained after the first IVF-ICSI cycle. Finally, a recent meta-analysis including five series of rectovaginal and colorectal endometriosis reported a PR of only $11.9 \%$ in women with concomitant adenomyosis while the PR was $43.0 \%$ in those without [15].

Another limiting factor is determining when to opt for either expectant management or IVF-ICSI treatment after colorectal surgery. One previous study demonstrated that the ASRM classification has a relatively low accuracy in predicting fertility outcomes [25]. Adamson et al. recommended the use of an Endometriosis Fertility Index (EFI) taking into account various 
parameters including the woman's age, duration of infertility, prior pregnancies, AFS (American Fertility Society) endometriosis lesion and total score[16]. Tomassetti et al. published an external validation of the EFI showing a high correlation between the EFI and the time to spontaneous pregnancy with a cumulative overall pregnancy rate at 12 months of 45.5\% ranging from $16.7 \%$ for EFI scores $0-3$ to $62.5 \%$ for EFI scores 9-10 [60]. Despite these results, the authors concluded that the EFI score had a moderate performance in predicting PR. Moreover, the EFI does not take into account the impact of DIE. In this specific condition, Ballester et al. [61] developed a nomogram to predict the PR after an IVFCSI cycle in women with DIE and identified several criteria including the woman's age, the anti-Müllerian hormone (AMH) serum level, and the number of ICSI-IVF cycles. While this well-calibrated model predicts clinical PR in infertile women with DIE, it is not specific to colorectal endometriosis and thus further analysis is justified.

Moreover, as mentioned in a recent review on DIE, the results of surgery on fertility have to be interpreted with caution to take into account not only tubal patency but also other infertility determining factors such as ovarian reserve, evaluated by AMH serum level, and sonographic follicle antral count as well as sperm characteristics [21]. Moreover, for women without an immediate desire to conceive, these parameters can be used to opt for ovarian or oocyte cryopreservation.

Finally, when starting a pregnancy with in situ deep infiltrating endometriosis, women have to be informed on the potential higher complication rate. Indeed, Saraswat et al. [62] reported a higher rates of miscarriage, ectopic pregnancy, antepartum and postpartum hemorrhage, placenta praevia and preterm birth compared to patients without endometriosis.

\section{Conclusion}


Our review underlines the lack of data from randomized trials to determine the surgical management of women with colorectal endometriosis and associated infertility. While some studies have identified a potential benefit of surgery on fertility outcomes, further investigations are required to determine fertility outcomes according to surgical procedures and whether surgical management should be first-intention or restricted to failure of MAR. 


\section{REFERENCES}

1. Giudice LC, Kao LC. Endometriosis. Lancet Lond. Engl. 2004;364:1789-99.

2. Chapron C, Jacob S, Dubuisson JB, Vieira M, Liaras E, Fauconnier A. Laparoscopically assisted vaginal management of deep endometriosis infiltrating the rectovaginal septum. Acta Obstet. Gynecol. Scand. 2001;80:349-54.

3. Koninckx PR, Meuleman C, Demeyere S, Lesaffre E, Cornillie FJ. Suggestive evidence that pelvic endometriosis is a progressive disease, whereas deeply infiltrating endometriosis is associated with pelvic pain. Fertil. Steril. 1991;55:759-65.

4. Koninckx PR, Ussia A, Adamyan L, Wattiez A, Donnez J. Deep endometriosis: definition, diagnosis, and treatment. Fertil. Steril. 2012;98:564-71.

5. Dunselman G a. J, Vermeulen N, Becker C, Calhaz-Jorge C, D'Hooghe T, De Bie B, et al. ESHRE guideline: management of women with endometriosis. Hum. Reprod. Oxf. Engl.

2014;29:400-12.

6. Macafee $\mathrm{CH}$, Greer HL. Intestinal endometriosis. A report of 29 cases and a survey of the literature. J. Obstet. Gynaecol. Br. Emp. 1960;67:539-55.

7. Weed JC, Ray JE. Endometriosis of the bowel. Obstet. Gynecol. 1987;69:727-30.

8. Zwas FR, Lyon DT. Endometriosis. An important condition in clinical gastroenterology. Dig. Dis. Sci. 1991;36:353-64.

9. Coronado C, Franklin RR, Lotze EC, Bailey HR, Valdés CT. Surgical treatment of symptomatic colorectal endometriosis. Fertil. Steril. 1990;53:411-6.

10. Dubernard G, Rouzier R, David-Montefiore E, Bazot M, Darai E. Use of the SF-36 questionnaire to predict quality-of-life improvement after laparoscopic colorectal resection for endometriosis. Hum. Reprod. Oxf. Engl. 2008;23:846-51.

11. Bailey HR, Ott MT, Hartendorp P. Aggressive surgical management for advanced colorectal endometriosis. Dis. Colon Rectum. 1994;37:747-53.

12. Ruffo G, Scopelliti F, Scioscia M, Ceccaroni M, Mainardi P, Minelli L. Laparoscopic colorectal resection for deep infiltrating endometriosis: analysis of 436 cases. Surg. Endosc. 2010;24:63-7.

13. Jerby BL, Kessler H, Falcone T, Milsom JW. Laparoscopic management of colorectal endometriosis. Surg. Endosc. 1999;13:1125-8.

14. Tran KT, Kuijpers HC, Willemsen WN, Bulten H. Surgical treatment of symptomatic rectosigmoid endometriosis. Eur. J. Surg. Acta Chir. 1996;162:139-41.

15. Vercellini P, Consonni D, Barbara G, Buggio L, Frattaruolo MP, Somigliana E. Adenomyosis and reproductive performance after surgery for rectovaginal and colorectal 
endometriosis: a systematic review and meta-analysis. Reprod. Biomed. Online. 2014;28:704-13.

16. Adamson GD, Pasta DJ. Endometriosis fertility index: the new, validated endometriosis staging system. Fertil. Steril. 2010;94:1609-15.

17. Haas D, Wurm P, Shamiyeh A, Shebl O, Chvatal R, Oppelt P. Efficacy of the revised Enzian classification: a retrospective analysis. Does the revised Enzian classification solve the problem of duplicate classification in rASRM and Enzian? Arch. Gynecol. Obstet. 2013;287:941-5.

18. Meuleman C, Tomassetti C, D'Hoore A, Van Cleynenbreugel B, Penninckx F, Vergote I, et al. Surgical treatment of deeply infiltrating endometriosis with colorectal involvement.

Hum. Reprod. Update. 2011;17:311-26.

19. Zegers-Hochschild F, Adamson GD, de Mouzon J, Ishihara O, Mansour R, Nygren K, et al. International Committee for Monitoring Assisted Reproductive Technology (ICMART) and the World Health Organization (WHO) revised glossary of ART terminology, 2009. Fertil. Steril. 2009;92:1520-4.

20. Zegers-Hochschild F, Adamson GD, de Mouzon J, Ishihara O, Mansour R, Nygren K, et al. The International Committee for Monitoring Assisted Reproductive Technology (ICMART) and the World Health Organization (WHO) Revised Glossary on ART Terminology, 2009. Hum. Reprod. Oxf. Engl. 2009;24:2683-7.

21. Cohen J, Thomin A, Mathieu D'Argent E, Laas E, Canlorbe G, Zilberman S, et al. Fertility before and after surgery for deep infiltrating endometriosis with and without bowel involvement: a literature review. Minerva Ginecol. 2014;66:575-87.

22. Eijkemans MJC, Lintsen AME, Hunault CC, Bouwmans C a. M, Hakkaart L, Braat DDM, et al. Pregnancy chances on an IVF/ICSI waiting list: a national prospective cohort study. Hum. Reprod. Oxf. Engl. 2008;23:1627-32.

23. Vercellini P, Barbara G, Buggio L, Frattaruolo MP, Somigliana E, Fedele L. Effect of patient selection on estimate of reproductive success after surgery for rectovaginal endometriosis: literature review. Reprod. Biomed. Online. 2012;24:389-95.

24. Donnez J, Squifflet J. Complications, pregnancy and recurrence in a prospective series of 500 patients operated on by the shaving technique for deep rectovaginal endometriotic nodules. Hum. Reprod. Oxf. Engl. 2010;25:1949-58.

25. Vercellini P, Pietropaolo G, De Giorgi O, Daguati R, Pasin R, Crosignani PG. Reproductive performance in infertile women with rectovaginal endometriosis: is surgery worthwhile? Am. J. Obstet. Gynecol. 2006;195:1303-10.

26. Reich H, McGlynn F, Salvat J. Laparoscopic treatment of cul-de-sac obliteration secondary to retrocervical deep fibrotic endometriosis. J. Reprod. Med. 1991;36:516-22.

27. Nezhat C, Nezhat F, Pennington E. Laparoscopic treatment of infiltrative rectosigmoid colon and rectovaginal septum endometriosis by the technique of videolaparoscopy and the CO2 laser. Br. J. Obstet. Gynaecol. 1992;99:664-7. 
28. Donnez J, Nisolle M, Casanas-Roux F, Bassil S, Anaf V. Rectovaginal septum, endometriosis or adenomyosis: laparoscopic management in a series of 231 patients. Hum. Reprod. Oxf. Engl. 1995;10:630-5.

29. Fedele L, Bianchi S, Zanconato G, Bettoni G, Gotsch F. Long-term follow-up after conservative surgery for rectovaginal endometriosis. Am. J. Obstet. Gynecol. 2004;190:1020 4.

30. Roman H, Tuech JJ. Laparoscopic and transanal excision of large lower- and mid-rectal deep endometriotic nodules: the Rouen technique. Fertil. Steril. 2014;102:e7.

31. Barri PN, Coroleu B, Tur R, Barri-Soldevila PN, Rodríguez I. Endometriosis-associated infertility: surgery and IVF, a comprehensive therapeutic approach. Reprod. Biomed. Online. 2010;21:179-85.

32. Stepniewska A, Pomini P, Bruni F, Mereu L, Ruffo G, Ceccaroni M, et al. Laparoscopic treatment of bowel endometriosis in infertile women. Hum. Reprod. Oxf. Engl.

2009;24:1619-25.

33. Acién P, Núñez C, Quereda F, Velasco I, Valiente M, Vidal V. Is a bowel resection necessary for deep endometriosis with rectovaginal or colorectal involvement? Int. J. Womens Health. 2013;5:449-55.

34. Roman H, Quibel S, Auber M, Muszynski H, Huet E, Marpeau L, et al. Recurrences and fertility after endometrioma ablation in women with and without colorectal endometriosis: a prospective cohort study. Hum. Reprod. Oxf. Engl. 2015;30:558-68.

35. Opøien HK, Fedorcsak P, Omland AK, Abyholm T, Bjercke S, Ertzeid G, et al. In vitro fertilization is a successful treatment in endometriosis-associated infertility. Fertil. Steril. 2012;97:912-8.

36. Mathieu d'Argent E, Coutant C, Ballester M, Dessolle L, Bazot M, Antoine J-M, et al. Results of first in vitro fertilization cycle in women with colorectal endometriosis compared with those with tubal or male factor infertility. Fertil. Steril. 2010;94:2441-3.

37. Ballester M, d'Argent EM, Morcel K, Belaisch-Allart J, Nisolle M, Daraï E. Cumulative pregnancy rate after ICSI-IVF in patients with colorectal endometriosis: results of a multicentre study. Hum. Reprod. Oxf. Engl. 2012;27:1043-9.

38. Meuleman C, Tomassetti C, Wolthuis A, Van Cleynenbreugel B, Laenen A, Penninckx F, et al. Clinical outcome after radical excision of moderate-severe endometriosis with or without bowel resection and reanastomosis: a prospective cohort study. Ann. Surg. 2014;259:522-31.

39. Daraï E, Lesieur B, Dubernard G, Rouzier R, Bazot M, Ballester M. Fertility after colorectal resection for endometriosis: results of a prospective study comparing laparoscopy with open surgery. Fertil. Steril. 2011;95:1903-8.

40. Redwine DB, Wright JT. Laparoscopic treatment of complete obliteration of the cul-desac associated with endometriosis: long-term follow-up of en bloc resection. Fertil. Steril. 2001;76:358-65. 
41. Fleisch MC, Xafis D, De Bruyne F, Hucke J, Bender HG, Dall P. Radical resection of invasive endometriosis with bowel or bladder involvement--long-term results. Eur. J. Obstet. Gynecol. Reprod. Biol. 2005;123:224-9.

42. Lyons SD, Chew SSB, Thomson AJM, Lenart M, Camaris C, Vancaillie TG, et al. Clinical and quality-of-life outcomes after fertility-sparing laparoscopic surgery with bowel resection for severe endometriosis. J. Minim. Invasive Gynecol. 2006;13:436-41.

43. Ghezzi F, Cromi A, Ciravolo G, Rampinelli F, Braga M, Boni L. A new laparoscopictransvaginal technique for rectosigmoid resection in patients with endometriosis. Fertil. Steril. 2008;90:1964-8.

44. Ferrero S, Anserini P, Abbamonte LH, Ragni N, Camerini G, Remorgida V. Fertility after bowel resection for endometriosis. Fertil. Steril. 2009;92:41-6.

45. Meuleman C, D'Hoore A, Van Cleynenbreugel B, Beks N, D'Hooghe T. Outcome after multidisciplinary $\mathrm{CO} 2$ laser laparoscopic excision of deep infiltrating colorectal endometriosis. Reprod. Biomed. Online. 2009;18:282-9.

46. Daraï E, Carbonnel M, Dubernard G, Lavoué V, Coutant C, Bazot M, et al. Determinant factors of fertility outcomes after laparoscopic colorectal resection for endometriosis. Eur. J. Obstet. Gynecol. Reprod. Biol. 2010;149:210-4.

47. Kavallaris A, Chalvatzas N, Hornemann A, Banz C, Diedrich K, Agic A. 94 months follow-up after laparoscopic assisted vaginal resection of septum rectovaginale and rectosigmoid in women with deep infiltrating endometriosis. Arch. Gynecol. Obstet. 2011;283:1059-64.

48. Possover M, Diebolder H, Plaul K, Schneider A. Laparascopically assisted vaginal resection of rectovaginal endometriosis. Obstet. Gynecol. 2000;96:304-7.

49. Keckstein J, Wiesinger H. Deep endometriosis, including intestinal involvement--the interdisciplinary approach. Minim. Invasive Ther. Allied Technol. MITAT Off. J. Soc. Minim. Invasive Ther. 2005;14:160-6.

50. Mohr C, Nezhat FR, Nezhat CH, Seidman DS, Nezhat CR. Fertility considerations in laparoscopic treatment of infiltrative bowel endometriosis. JSLS J. Soc. Laparoendosc. Surg. Soc. Laparoendosc. Surg. 2005;9:16-24.

51. Minelli L, Fanfani F, Fagotti A, Ruffo G, Ceccaroni M, Mereu L, et al. Laparoscopic colorectal resection for bowel endometriosis: feasibility, complications, and clinical outcome. Arch. Surg. Chic. Ill 1960. 2009;144:234-9; discussion 239.

52. Meuleman C, Tomassetti C, D'Hoore A, Buyens A, Van Cleynenbreugel B, Fieuws S, et al. Clinical outcome after $\mathrm{CO} \square$ laser laparoscopic radical excision of endometriosis with colorectal wall invasion combined with laparoscopic segmental bowel resection and reanastomosis. Hum. Reprod. Oxf. Engl. 2011;26:2336-43.

53. Jelenc F, Ribič-Pucelj M, Juvan R, Kobal B, Sinkovec J, Salamun V. Laparoscopic rectal resection of deep infiltrating endometriosis. J. Laparoendosc. Adv. Surg. Tech. A.

2012;22:66-9. 
54. Vitobello D, Fattizzi N, Santoro G, Rosati R, Baldazzi G, Bulletti C, et al. Robotic surgery and standard laparoscopy: a surgical hybrid technique for use in colorectal endometriosis. J. Obstet. Gynaecol. Res. 2013;39:217-22.

55. Neme RM, Schraibman V, Okazaki S, Maccapani G, Chen WJ, Domit CD, et al. Deep infiltrating colorectal endometriosis treated with robotic-assisted rectosigmoidectomy. JSLS J. Soc. Laparoendosc. Surg. Soc. Laparoendosc. Surg. 2013;17:227-34.

56. Tarjanne S, Heikinheimo O, Mentula M, Härkki P. Complications and long-term followup on colorectal resections in the treatment of deep infiltrating endometriosis extending to bowel wall. Acta Obstet. Gynecol. Scand. 2015;94:72-9.

57. Malzoni M, Di Giovanni A, Exacoustos C, Lannino G, Capece R, Perone C, et al. Feasibility and Safety of Laparoscopic-Assisted Bowel Segmental Resection for Deep Infiltrating Endometriosis: A Retrospective Cohort Study With Description of Technique. J. Minim. Invasive Gynecol. [Internet]. 2015 [cited 2016 Mar 10]; Available from: http://linkinghub.elsevier.com/retrieve/pii/S1553465015016040

58. Capelle A, Lepage J, Langlois C, Lefebvre C, Dewailly D, Collinet P, et al. [Surgery for deep infiltrating endometriosis before in vitro fertilization: no benefit for fertility?]. Gynécologie Obstétrique Fertil. 2015;43:109-16.

59. Roman H. Colorectal endometriosis and pregnancy wish: why doing primary surgery. Front. Biosci. Sch. Ed. 2015;7:83-93.

60. Tomassetti C, Geysenbergh B, Meuleman C, Timmerman D, Fieuws S, D'Hooghe T. External validation of the endometriosis fertility index (EFI) staging system for predicting non-ART pregnancy after endometriosis surgery. Hum. Reprod. Oxf. Engl. 2013;28:1280-8.

61. Ballester M, Oppenheimer A, d'Argent EM, Touboul C, Antoine J-M, Coutant C, et al. Nomogram to predict pregnancy rate after ICSI-IVF cycle in patients with endometriosis. Hum. Reprod. Oxf. Engl. 2012;27:451-6.

62. Saraswat L, Ayansina DT, Cooper KG, Bhattacharya S, Miligkos D, Horne AW, et al. Pregnancy outcomes in women with endometriosis: a national record linkage study. BJOG Int. J. Obstet. Gynaecol. 2016; 


\section{Condensation:}

Colorectal resection is associated with an increased in pregnancy rate in patients with prior infertility associated with endometriosis or wishing to conceive without true infertility. 
Table 1: Spontaneous pregnancy and after MAR in patients with colorectal endometriosis.

\begin{tabular}{|c|c|c|c|c|c|c|c|}
\hline \multirow[t]{2}{*}{ Authors } & \multirow[t]{2}{*}{$\begin{array}{c}\text { Characteristics of } \\
\text { the study }\end{array}$} & \multirow[t]{2}{*}{$\begin{array}{l}\text { Women } \\
\text { (n) }\end{array}$} & \multirow[t]{2}{*}{$\begin{array}{c}\text { Infertile } \\
\text { Women (n) }\end{array}$} & \multirow[t]{2}{*}{$\begin{array}{l}\text { Spontaneous } \\
\text { pregnancies }\end{array}$} & \multicolumn{2}{|c|}{$\begin{array}{c}\text { MAR } \\
\text { pregnancies } \\
\mathrm{N}(\%)\end{array}$} & \multirow[t]{2}{*}{$\begin{array}{c}\text { Overall } \\
\text { pregnancie } \\
\mathrm{S} \\
\mathrm{N}(\%) \\
\end{array}$} \\
\hline & & & & & IUI & IVF & \\
\hline Ballester [37] & $\begin{array}{l}\text { No surgery. First } \\
\text { intention IVF- } \\
\text { ICSI }\end{array}$ & 75 & 75 & NA & 0 & $\begin{array}{c}32 \\
(43)\end{array}$ & $\begin{array}{c}32(43) \\
\mathbf{9 5 \%} \mathbf{C I}=(\mathbf{3 1}- \\
\mathbf{5 4})\end{array}$ \\
\hline $\begin{array}{c}\text { Stepniewska } \\
{[32]}\end{array}$ & $\begin{array}{c}\text { Other DIE } \\
\text { lesions removed* }\end{array}$ & 40 & 39 & $7(18)$ & 0 & $\begin{array}{c}1 \\
(2.5)\end{array}$ & $\begin{array}{c}8(20) \\
95 \% \mathrm{CI}=(7-34)\end{array}$ \\
\hline Acien [33] & $\begin{array}{c}\text { Other DIE } \\
\text { lesions removed* }\end{array}$ & 23 & 10 & $6(60)$ & 0 & $\begin{array}{c}1 \\
(10) \\
\end{array}$ & $\begin{array}{c}7(70) \\
95 \% \mathrm{CI}=(35- \\
104) \\
\end{array}$ \\
\hline TOTAL & & 138 & 124 & $\begin{array}{l}13(26.5)^{*} \\
95 \% \text { CI }(14-39)\end{array}$ & $\begin{array}{r}34( \\
95 \% \mathrm{C}\end{array}$ & $\begin{array}{l}7.4) \\
(19-35)\end{array}$ & $\begin{array}{l}47(37.9 \%) \\
95 \% \text { CI (29-47) }\end{array}$ \\
\hline
\end{tabular}

* leaving in situ colorectal endometriosis 
Table 2: Fertility (Spontaneous and after MAR) after colorectal surgery for endometriosis

\begin{tabular}{|c|c|c|c|c|c|c|}
\hline \multirow{2}{*}{ Authors } & \multirow{2}{*}{$\begin{array}{c}\text { Women } \\
\mathbf{N}\end{array}$} & \multirow{2}{*}{$\begin{array}{c}\text { Women } \\
\text { without } \\
\text { proved } \\
\text { infertility }\end{array}$} & \multirow{2}{*}{$\begin{array}{l}\text { Spontaneous } \\
\text { pregnancies } \\
\text { N (\%) }\end{array}$} & MAR & $\begin{array}{l}\text { regnancies } \\
(\%)\end{array}$ & \multirow{2}{*}{$\begin{array}{c}\text { Overall } \\
\text { pregnancies } \\
\text { N }(\%)\end{array}$} \\
\hline & & & & IUI & IVF & \\
\hline \multicolumn{7}{|c|}{ Women without proved infertility } \\
\hline Coronado [9] & 77 & 33 & $13(39.4)$ & 0 & 0 & $13(39.4)$ \\
\hline Jerby [13] & 30 & 7 & $3(42.9)$ & 0 & 0 & $3(42.9)$ \\
\hline Redwine [40] & 84 & 28 & $7(25)$ & 0 & $5(17.9)$ & $12(42.9)$ \\
\hline Fleisch [41] & 23 & 17 & $3(17.6)$ & 0 & $1(5.1)$ & $4(23.5)$ \\
\hline Lyons [42] & 7 & 3 & $3(100)$ & 0 & 0 & $3(100)$ \\
\hline Ghezzi [43] & 33 & 13 & $4(30.8)$ & 0 & 0 & $4(30.8)$ \\
\hline Ferrero [44] & 46 & 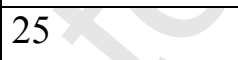 & $7(28)$ & $2(8)$ & $4(16)$ & $13(52)$ \\
\hline Meuleman [45] & 56 & 33 & $7(21.2)$ & $1(3)$ & $8(24.2)$ & $16(48.5)$ \\
\hline Darai [46] & 83 & 55 & $20(46.5)$ & 0 & $9(16.4)$ & $29(52.7)$ \\
\hline Kavallaris [47] & 55 & 17 & $7(41,2)$ & 0 & $4(23,5)$ & $11(64,7)$ \\
\hline Darai [39] & 52 & 13 & $2(15.4)$ & 0 & $4(30.8)$ & $6(46.2)$ \\
\hline \multirow{2}{*}{$\begin{array}{l}\text { TOTAL } \\
\text { women without } \\
\text { proved } \\
\text { infertility }\end{array}$} & & & $76(31.1)$ & $3(1.2)$ & $35(14.3)$ & \multirow{2}{*}{$\begin{array}{c}114(46.7) \\
95 \% \text { CI (40-53) }\end{array}$} \\
\hline & 546 & 244 & 95\% CI (25-37) & \multicolumn{2}{|c|}{$\begin{array}{c}38(15.5) \\
95 \% \text { CI }(11-20)\end{array}$} & \\
\hline
\end{tabular}




\section{Women with proved infertility}

\begin{tabular}{|c|c|c|c|c|c|c|}
\hline \multirow[t]{2}{*}{ Authors } & \multirow{2}{*}{$\begin{array}{c}\text { Women } \\
\mathbf{N}\end{array}$} & \multirow{2}{*}{$\begin{array}{l}\text { Infertile } \\
\text { women }\end{array}$} & \multirow{2}{*}{$\begin{array}{c}\text { Spontaneous } \\
\text { pregnancies } \\
\text { N (\%) }\end{array}$} & \multicolumn{2}{|c|}{$\begin{array}{c}\text { MAR pregnancies } \\
\text { N }(\%)\end{array}$} & \multirow{2}{*}{$\begin{array}{c}\text { Overall } \\
\text { pregnancies } \\
\mathrm{N}(\%)\end{array}$} \\
\hline & & & & IUI & IVF & \\
\hline Possover [48] & 34 & 15 & $8(53.3)$ & 0 & 0 & $8(53.3)$ \\
\hline Keckstein [49] & 142 & 36 & $18(50)$ & 0 & 0 & $18(50)$ \\
\hline Mohr [50] & 87 & 56 & $19(33.9)$ & 0 & 0 & $19(33.9)$ \\
\hline Ferrero [44] & 46 & 21 & $2(9.5)$ & $3(8)$ & $4(19)$ & $9(42.9)$ \\
\hline Minelli [51] & 343 & 113 & $13(11.5)$ & 0 & $51(45.1)$ & $64(56.6)$ \\
\hline $\begin{array}{l}\text { Stepniewska } \\
{[32]}\end{array}$ & 60 & 48 & $12(25)$ & 0 & $5(10.4)$ & $17(35.4)$ \\
\hline Meuleman [52] & 45 & 28 & $9(32.1)$ & 0 & $5(17.9)$ & $14(50.0)$ \\
\hline Darai [39] & 52 & 15 & $4(26.7)$ & 0 & $1(6.7)$ & $5(33.3)$ \\
\hline Jelenc [53] & 56 & 14 & $8(57.1)$ & 0 & $2(14.3)$ & $10(71.4)$ \\
\hline Vitobello [54] & 7 & 7 & $2(28.6)$ & 0 & 0 & $2(28.6)$ \\
\hline Tarjanne [56] & 164 & 88 & $21(23.9)$ & 0 & $28(33)$ & $49(55.7)$ \\
\hline Malzoni [57] & 248 & 72 & $44(61)$ & 0 & $6(8.3)$ & $50(69)$ \\
\hline Meuleman [38] & 76 & 54 & \begin{tabular}{|l|}
$13(24)$ \\
\end{tabular} & $1(1.9)$ & $13(24)$ & $27(50)$ \\
\hline Roman [34] & 52 & 38 & $15(39.5)$ & 0 & $10(26.3)$ & $2565.8)$ \\
\hline Neme [55] & 10 & 6 & 4 (66.7) & 0 & $2(33.3)$ & $6(100)$ \\
\hline \multirow{2}{*}{$\begin{array}{l}\text { TOTAL } \\
\text { women with }\end{array}$} & & & $192(31.4)$ & $4(0.7)$ & $127(21)$ & \multirow{2}{*}{$\begin{array}{c}323(52.9) \\
95 \% \text { CI (49-57) }\end{array}$} \\
\hline & 1422 & 611 & $95 \%$ CI (28-35) & $\begin{array}{r}13 \\
95 \%\end{array}$ & $\begin{array}{l}(21.4) \\
I(18-25)\end{array}$ & \\
\hline
\end{tabular}




\begin{tabular}{|l|c|c|c|c|c|} 
TOTAL & \multirow{2}{*}{1968} & $855(45.7 \%)$ & $268(31.4)$ & $169(19.8)$ & $437(51.1)$ \\
& & & $95 \%$ CI (28-34) & $95 \%$ CI (17-22) & 95\% CI (48-54) \\
\hline
\end{tabular}


Figure 2: Spontaneous pregnancy rate in patients after DIE resection but leaving in situ colorectal endometriosis

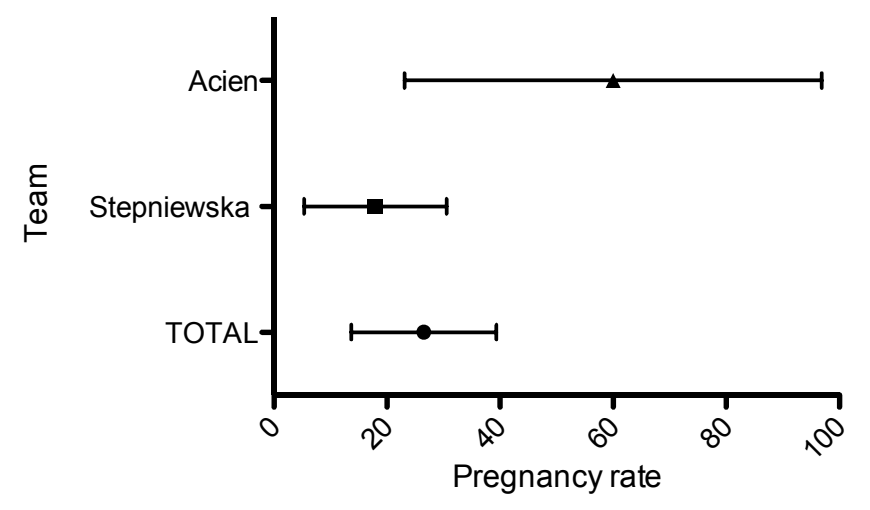

PR: $26.5 \%(95 \% \mathrm{CI}=14-39)$

Figure 3: Pregnancy rate after MAR in patients undergoing DIE resection but leaving in situ colorectal endometriosis or no surgery

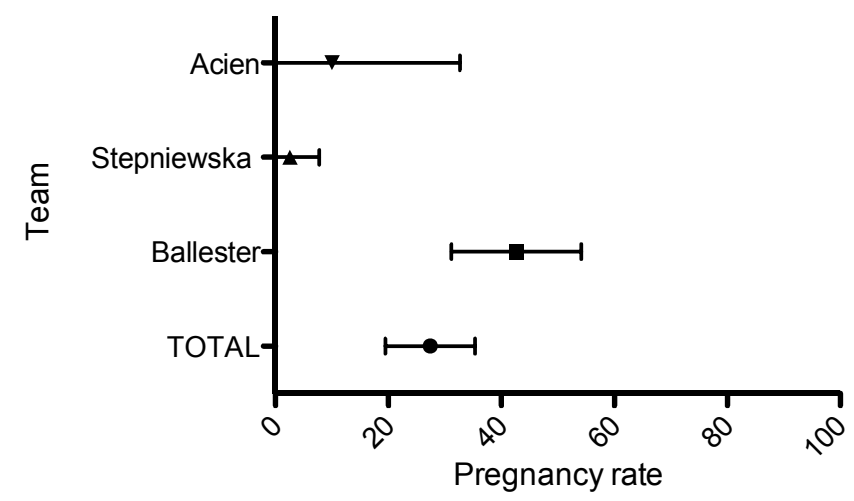

$P R=27.4 \%(95 \% \quad C I=19-35)$ 
Figure 4: Spontaneous fertility after colorectal surgery for endometriosis

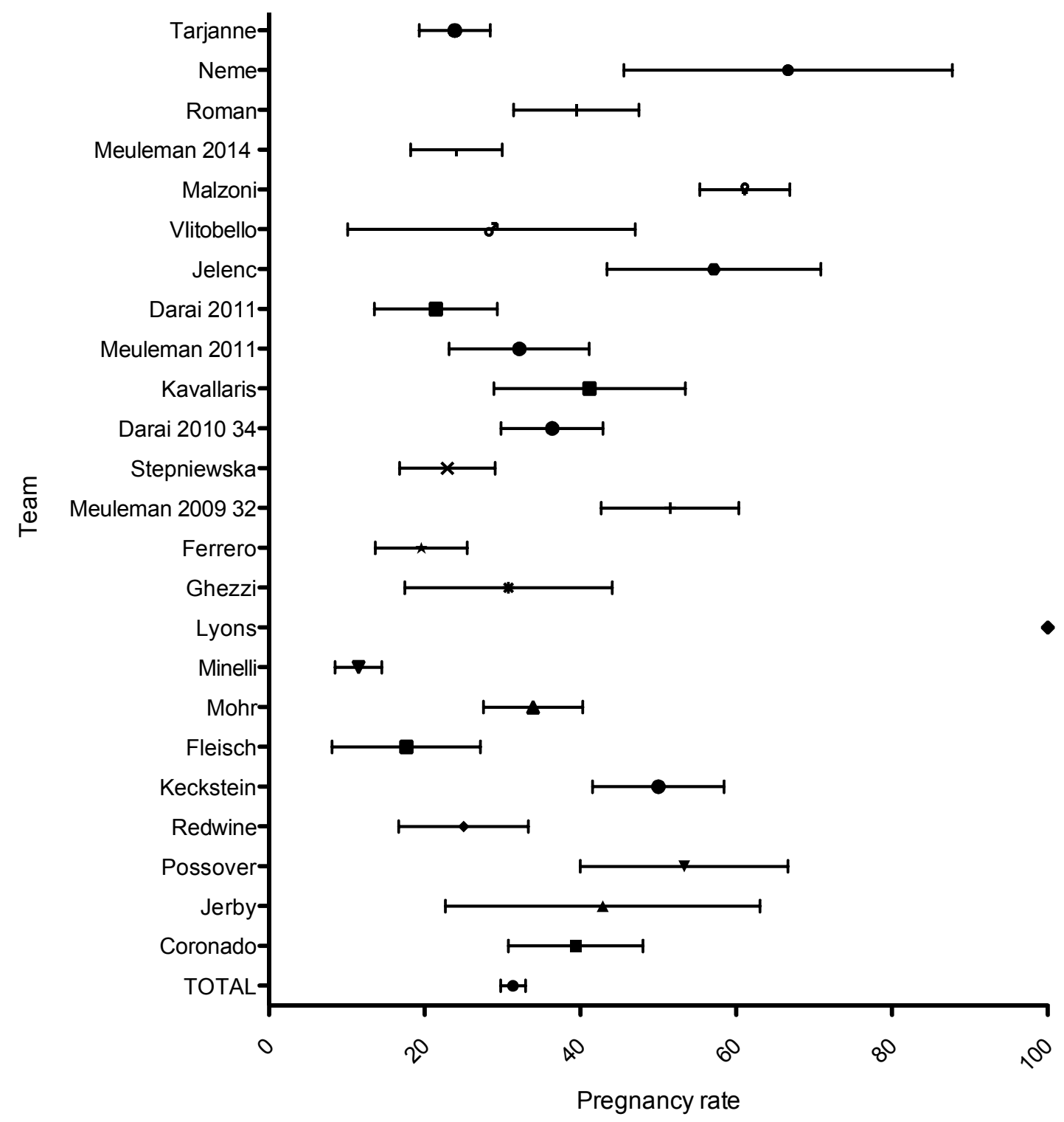

PR: 31.4\%; 95\% CI (28-34) 
Figure 5: Spontaneous fertility after colorectal surgery for endometriosis in patients with proved infertility

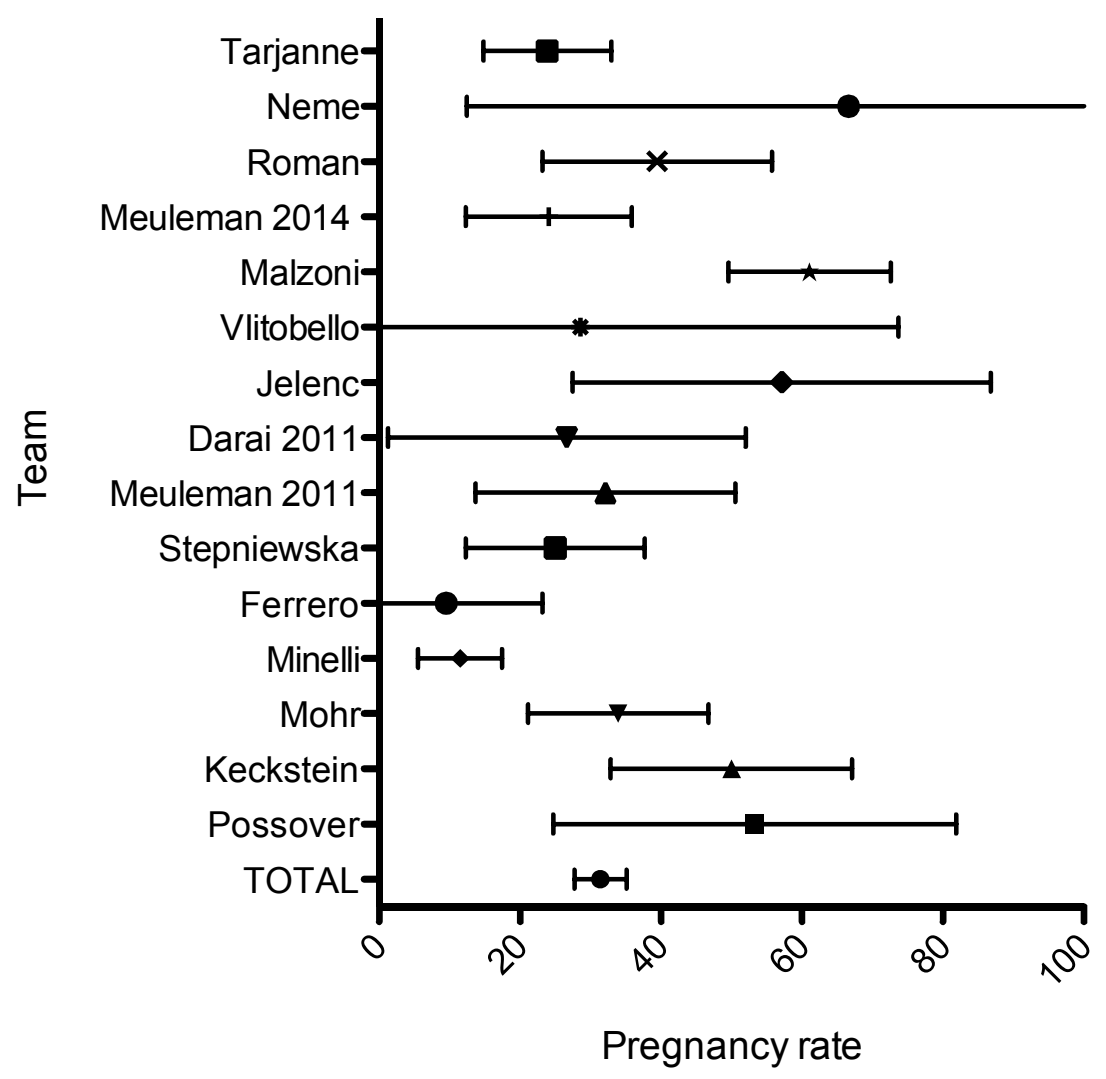

PR: 31.4\%; 95\% CI (28-35) 
Figure 6: Spontaneous fertility after colorectal surgery for endometriosis in patients without proved of infertility

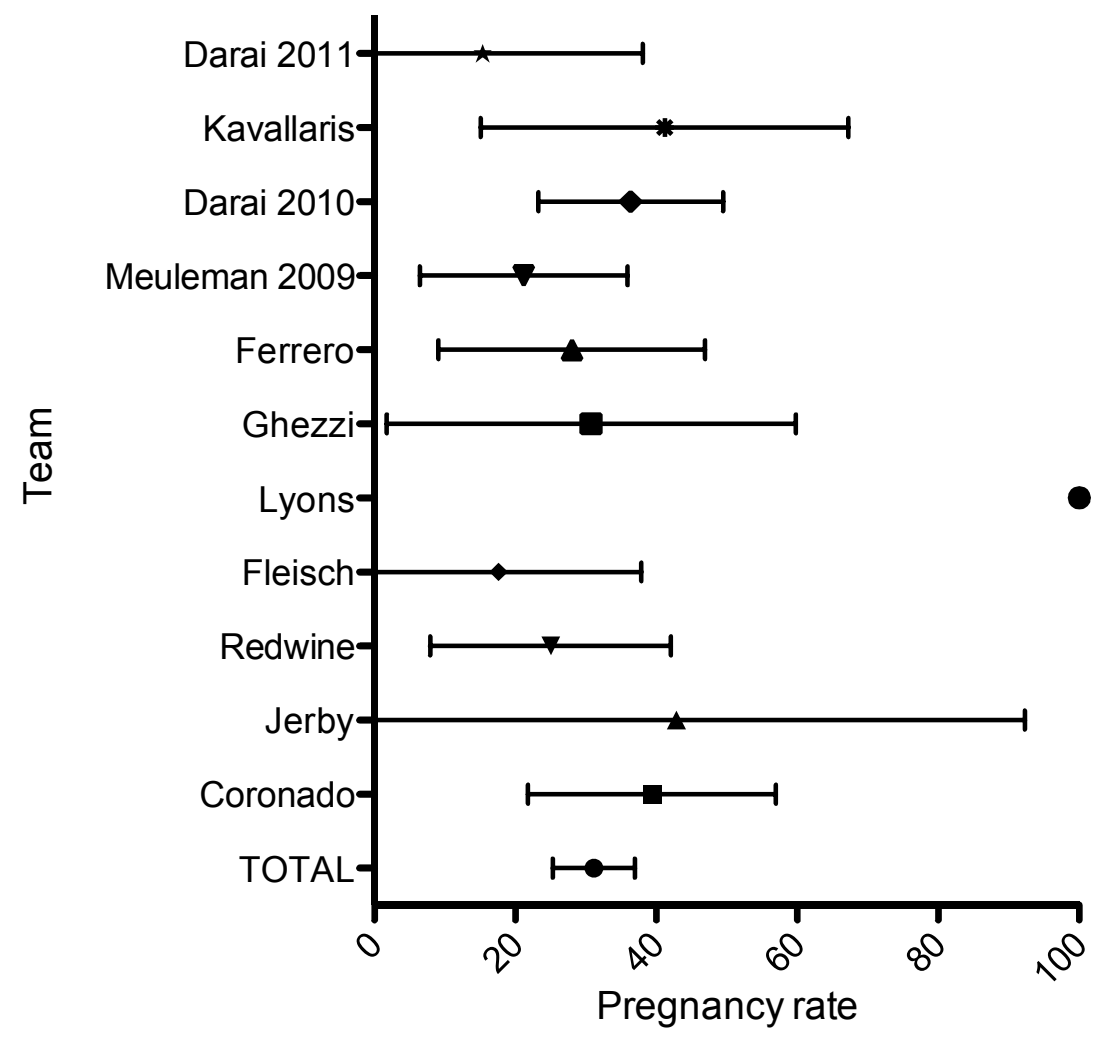

PR: 31.1\%; 95\% CI (25-37) 
Figure 7: Overall pregnancy rate after colorectal surgery for endometriosis.

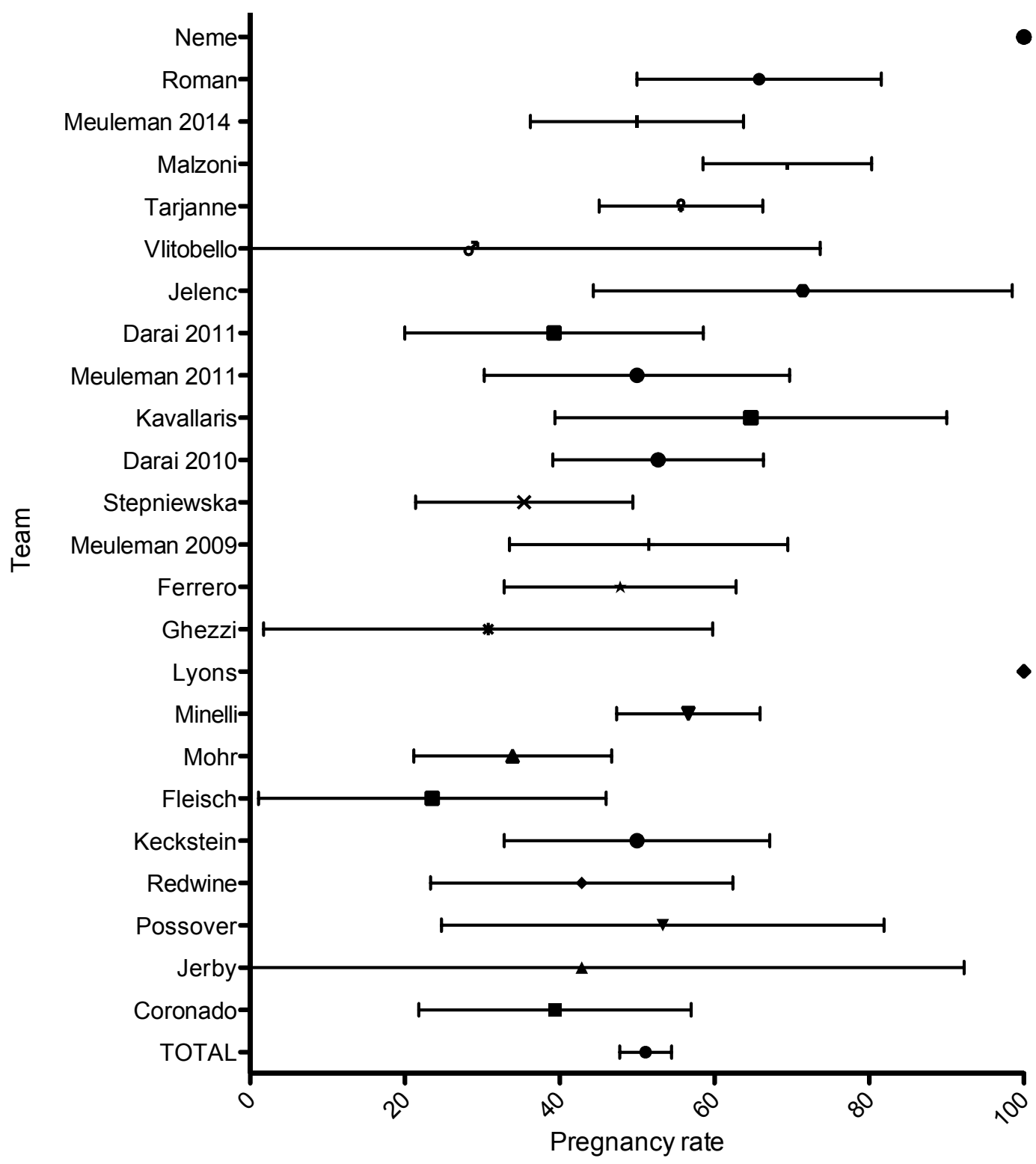

PR: 51.1\%; 95\% CI (48-54) 
Figure 8: Fertility after MAR (ART and IUI) and colorectal surgery for endometriosis

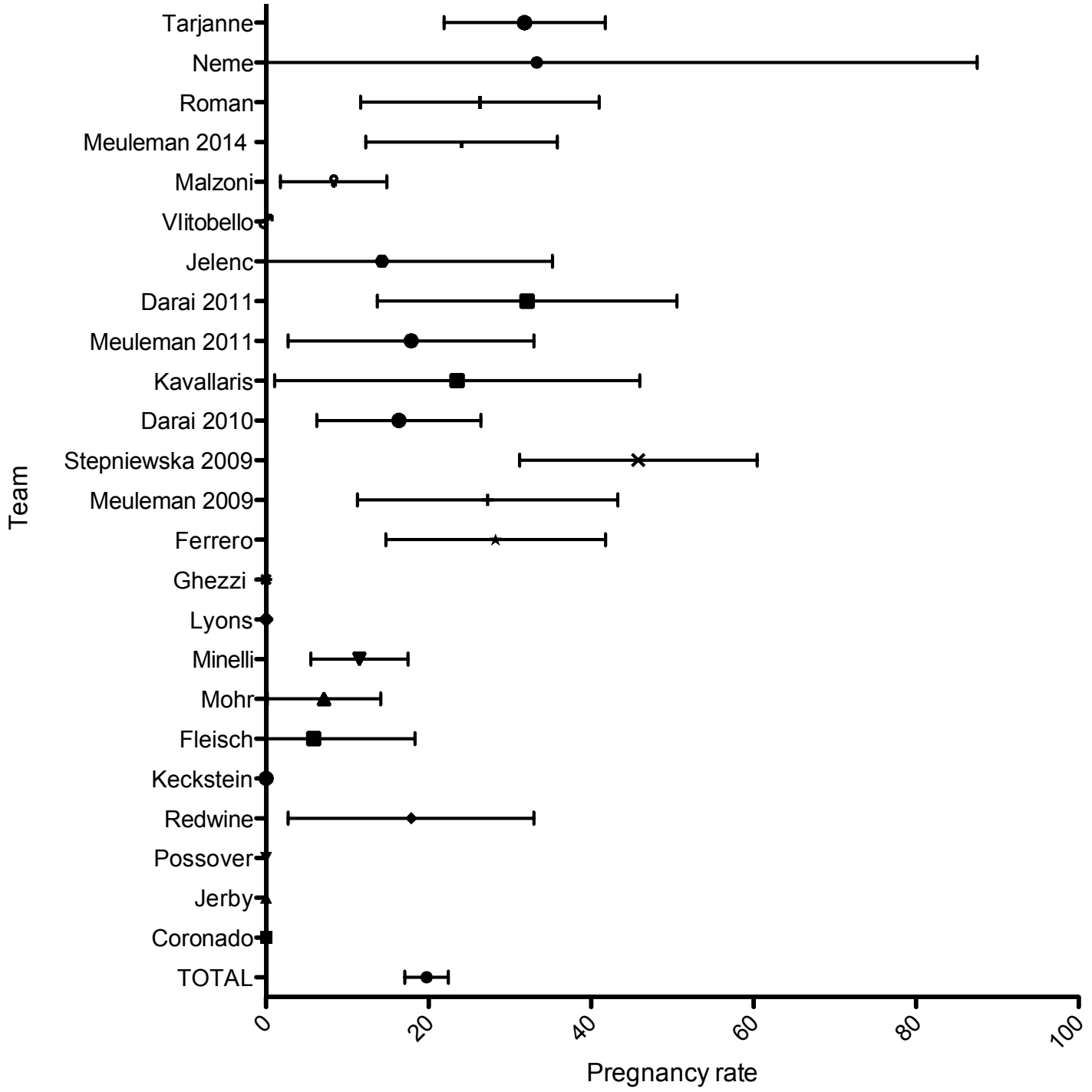

PR: $19.8 \%$; 95\% CI (17-22) 
Figure 9: Fertility after MAR (ART and IUI) and colorectal surgery for endometriosis in patients with proved infertility

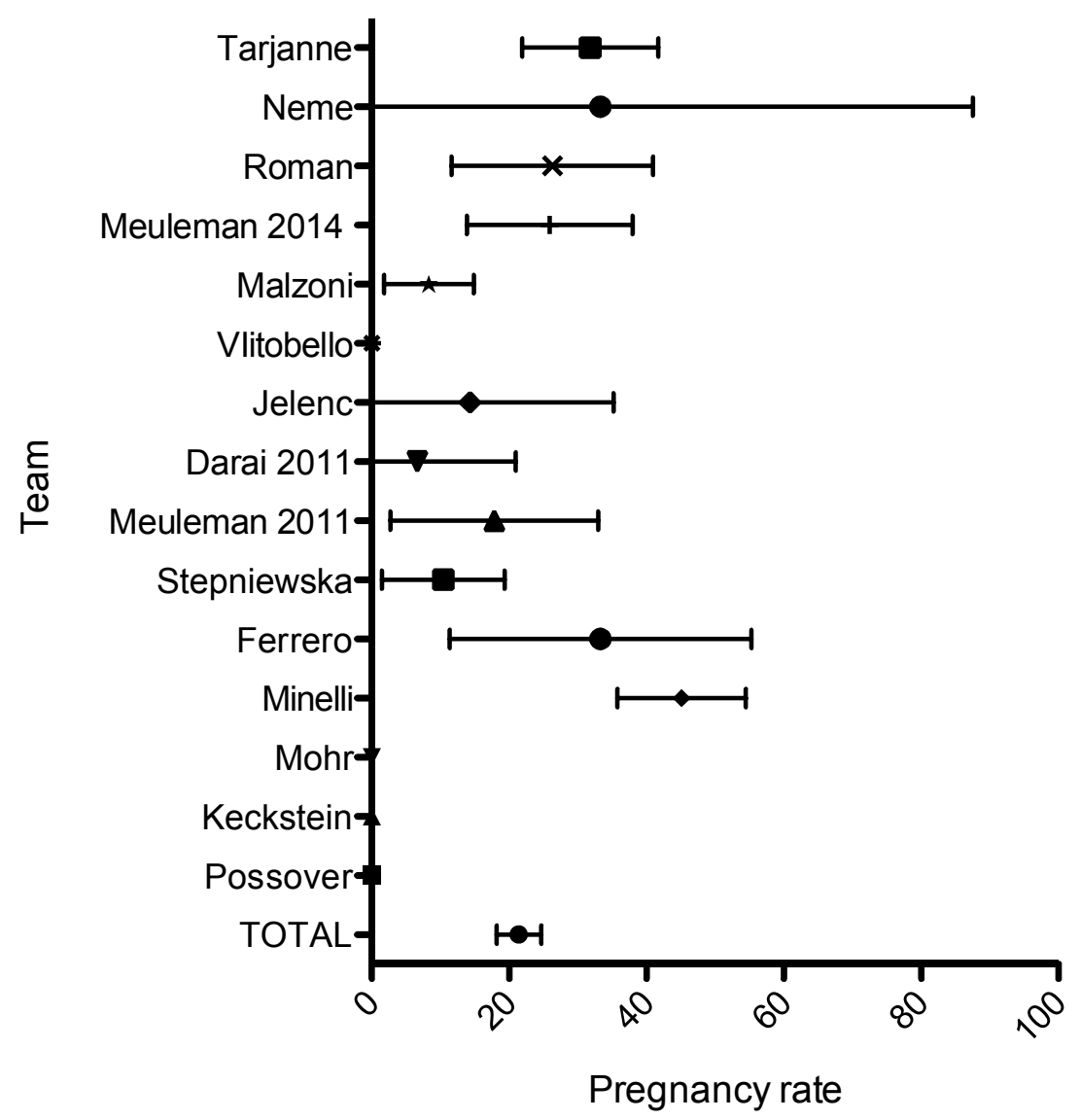

PR: 21.4\%; 95\% CI (18-25) 
Figure 10: Fertility after MAR (ART and IUI) and colorectal surgery for endometriosis in patients without proved infertility

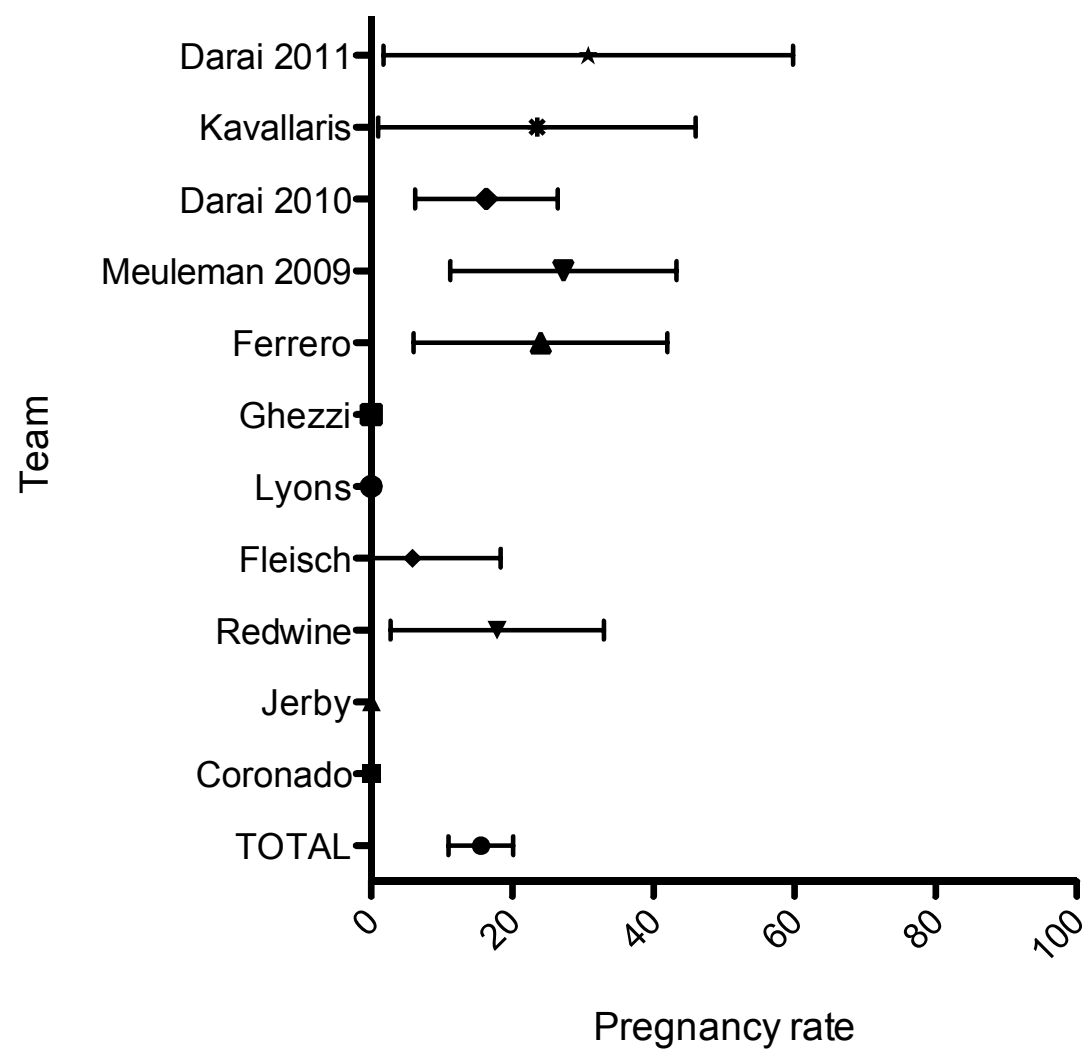

PR: $15.5 \% ; 95 \%$ CI (11-20) 
42 articles found for " colorectal endometriosis $"$ and " fertility " or " infertility "

\section{8 articles found for « colorectal} endometriosis " and "IVF »

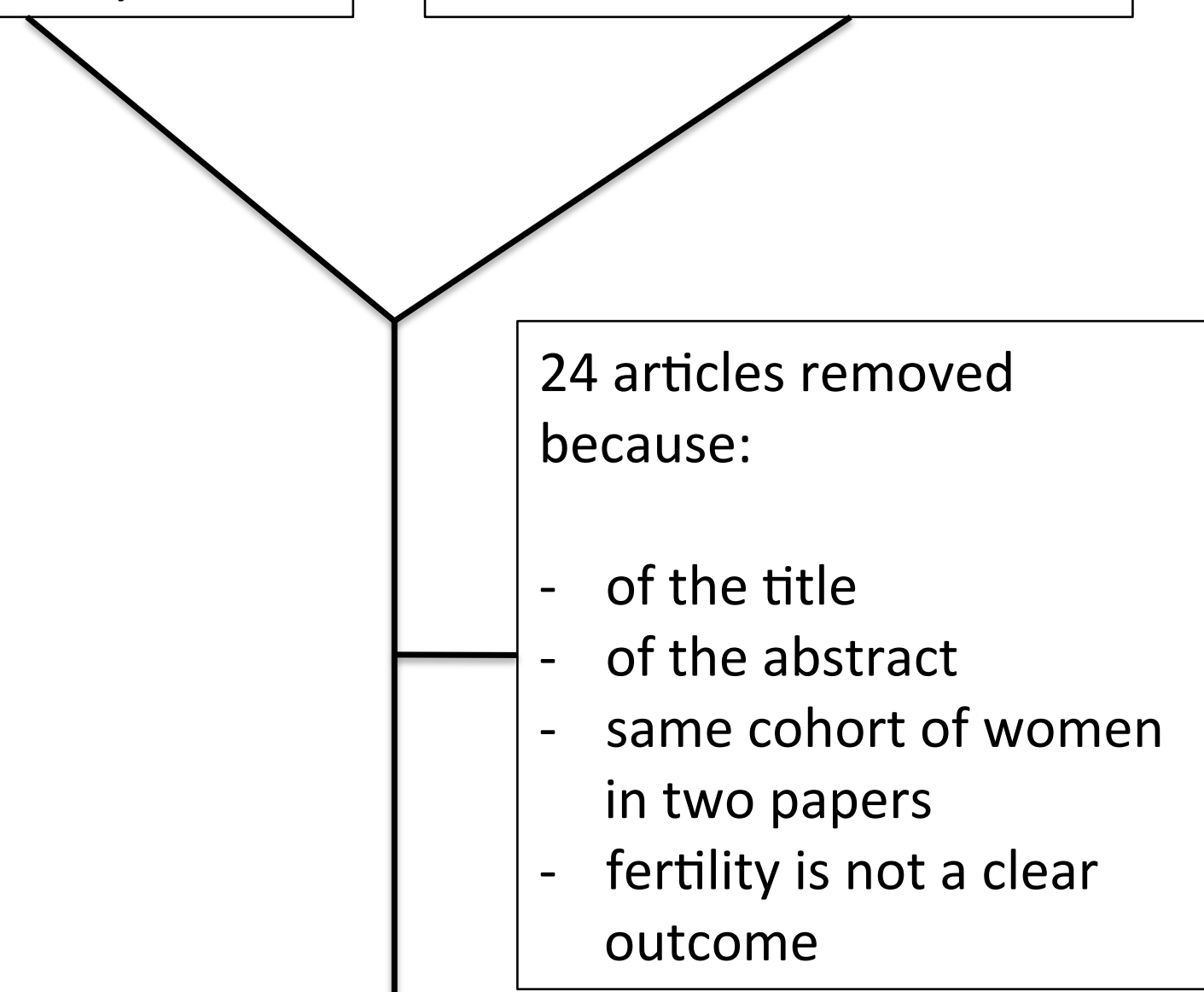

26 articles included in quantitative analysis 
Figure 1: Flowchart for literature review of colorectal endometriosis and fertility. 